\title{
ANÁLISE DA EXPANSÃO DA MANCHA URBANA NAS ÁREAS DE MANGUEZAL NA COMUNIDADE DO DIQUE DA VILA GILDA NO MUNICÍPIO DE SANTOS (SP)
}

\author{
Pâmela Pereira de Araújo ${ }^{(a)}$, Janaína Tinoco de Almeida ${ }^{(b)}$, Marcília Almeida Porto ${ }^{(c)}$, Jhonnes \\ Alberto $\mathrm{Vaz}^{(\mathrm{d})}$ \\ (a) Discente de Engenharia Ambiental/Universidade Católica de Santos, pamela.pereira011@ gmail.com \\ (b) Discente de Engenharia Ambiental/Universidade Católica de Santos, jantinoco@ gmail.com \\ (c) Discente de Engenharia Ambiental/Universidade Católica de Santos, engmaalmeida@gmail.com \\ (d) Laboratório de Sustentabilidade - Instituto de Pesquisas Científicas e Tecnológicas/Universidade Católica de \\ Santos, jhonnes.vaz@unisantos.br
}

Eixo: Uso e ocupação das terras e legislação ambiental

\begin{abstract}
Resumo
O presente estudo está localizado no Município de Santos (SP), que devido ao desenvolvimento econômico da região, tem áreas de ocupação irregular em regiões de manguezal. $O$ uso de geotecnologias fornece informações que permitem realizar estudos de séries históricas, possibilitando uma melhor visualização e compreensão da evolução da área em estudo. O objetivo deste trabalho é analisar a evolução da ocupação da comunidade do Dique da Vila Gilda em áreas de manguezal, utilizando um Sistema de Informações Geográficas. Foram utilizadas imagens de voos aerofotogramétricos de 4 datas distintas cedidas pela prefeitura do munícipio. A partir das imagens, foi realizado o mapeamento da área em estudo, verificando o crescimento das ocupações irregulares sobre a área de mangue ao longo do tempo. Nota-se a expansão da mancha urbana, totalizando em 2014, 195,7 mil m² de ocupação irregular e a supressão total da vegetação existente na área.
\end{abstract}

Palavras chave: Análise temporal. Geoprocessamento. Mancha urbana. Manguezal.

\section{Introdução}

A ocupação da Região Metropolitana da Baixada Santista - RMBS teve sua origem relacionada á sua localização na área costeira e a capacidade dessas áreas de exercer uma função de porto marítimo. Devido ao grande movimento de cargas pelo porto e linhas férreas, a região, Santos principalmente, sofreu com efeitos da urbanização de forma desordenada, ocasionando um grande impacto ambiental e afetando negativamente a população (INSTITUTO POLIS, 2012).

O munícipio de Santos apresenta diversas áreas de manguezal, porém, nas últimas décadas, muitas dessas áreas foram ocupadas irregularmente. Uma dessas ocupações, o Dique Vila Gilda, têm formado uma mancha urbana de moradias em palafitas que avança adentro da vegetação de mangue, uma área sensível e de importância para o funcionamento do ecossistema natural (FABIANO \& MUNIZ, 2010). 
O monitoramento dessas áreas pode ser realizado através da análise e georreferenciamento de imagens ortorretificadas da região (nos anos de 1962, 1986, 2003 e 2014), delimitando as áreas irregulares visíveis, possibilitando a avaliação do crescimento da mancha urbana sobre a área de mangue em $\mathrm{m}^{2}$ ao longo do tempo.

\subsection{Ocupação urbana de Santos e da comunidade do Dique Vila Gilda}

O Município de Santos está localizado na RMBS e apresenta uma área de 280,7 km2 sob as coordenadas $23^{\circ} 56^{\prime} 13^{\prime \prime} \mathrm{S} 46^{\circ} 19^{\prime} 30^{\prime \prime} \mathrm{O}$. É considerada a cidade que abriga a maior parte da população da RMBS, aproximadamente 420 mil (IBGE, 2010).

O crescimento e ocupação da região ocorreram com a chegada dos portugueses no século XIV. Dessa época até os dias atuais, a ocupação seguiu um padrão de planejamento baseado em três ações: porto, indústria e turismo (SIQUEIRA, 2007). Em Santos, a expansão se deu a partir da região central expandindo-se até 1950 por toda a região da ilha de São Vicente. No início do século 20, quando obras de saneamento possibilitaram a ocupação da orla da praia, iniciou-se a ocupação da faixa costeira, tornandose a área mais valorizada (INSTITUTO POLIS, 2012).

A comunidade do Dique Vila Gilda encontra-se na porção insular do município, região noroeste, as margens do rio Bugres e divisa com o município de São Vicente. Sua ocupação se deu por volta da década de 60 com a construção, às margens do Rio dos Bugres, de canais de drenagem e um dique.

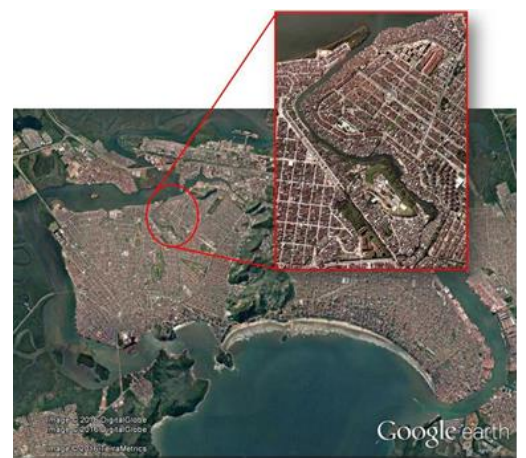

Figura 1: Localização da área da comunidade do Dique da Vila Gilda.

Na legislação ambiental, a Resolução CONAMA, n 303, de 20 de março de 2002, estipula a definição de manguezal, no $2^{\circ}$ artigo, inciso IX e constitui o mesmo como Área de Preservação Permanente - APP, no $3^{\circ}$ artigo, Inciso X, caracterizando assim a área do dique da Vila Gilda como Área de Preservação Permanente - APP, sendo também a maior favela sobre palafitas do Brasil (MMA, 2016). 
E também é considerada Área de Preservação Permanente pela Lei Federal no 12.651, de 25 de maio de 2012, no capítulo II, seção I, $4^{\circ}$ artigo, inciso I, alínea "b" uma faixa marginal de 50 metros, desde a borda da calha do leito regular para os cursos d'água de 10 a 50 metros, seja em zonas urbanas ou rurais (BRASIL, 2016).

A área em questão era dominada por extensos manguezais, vegetação de restinga e floresta atlântica. $\mathrm{O}$ Ministério do Meio Ambiente (2016), classifica manguezal como zona úmida, de transição entre ambientes terrestre e marinho, tendo a sua função específica dentro do ecossistema de regulagem e transporte de matéria orgânica. É um "berço" natural para diversas espécies, sendo de extrema importância por ser altamente produtiva e economicamente importante.

Devido à urbanização descontrolada, a região foi desmatada para a construção de palafitas, alterando intensamente a paisagem e degradando o local ocasionando na diminuição de produtividade, carregamento do solo, assoreamento do estuário e possível extinção de diversas espécies, além dos riscos a própria população (LIMA; OLIVEIRA, 2011).

\section{Metodologia de Trabalho}

Para este trabalho foram coletadas, junto a Prefeitura Municipal de Santos, imagens aéreas ortorretificadas dos anos de 1962, 1986, 2003 e 2014 da região da comunidade do Dique Vila Gilda. As imagens possuem escalas distintas para cada ano devido às distintas esferas que realizaram o sobrevoo e a escala do mesmo, sendo 1:25000 na imagem de 1962, 1:35000 na de 1986 e 1:1000 nas de 2003 e 2014. Essa diferença origina uma dificuldade na questão da diferença de precisão no momento da vetorização das áreas, porém, como o intuito do trabalho foi verificar a expansão da mancha urbana sobre a área de manguezal através da macro visualização da área, não foi considerado um problema que inviabilizasse o estudo.

Para o processamento das imagens, optou-se pelo uso do software QGIS versão, 2.14.3. As imagens de 1962 e 1986 foram georreferenciadas pelo software, para permitir processo de delimitação das áreas. O georreferenciamento das respectivas imagens foi feito com o método de transformação "Polinomial 1". Todas as imagens estão georreferenciadas no Sistema Geodésico de Referência SIRGAS 2000 (IBGE, 2005) e o Sistema de Projeção Cartográfica adotado foi o Universal Transversa de Mercator - UTM.

Foi realizado, a partir dessas imagens, o mapeamento da área em estudo nos anos selecionados, verificando as áreas vazias, onde ainda não é visível a ocupação por palafitas e outras formas de moradias, e as áreas já ocupadas. Para o cálculo das áreas foi utilizado o próprio recurso do software que gera automaticamente, com base no comando "ábaco", a informação referente. A delimitação das áreas de 
manguezal na imagem de 1962 foi feita com base no trabalho de Santos (2009). Após a delimitação das áreas foi possível verificar o processo de expansão urbana da área ao longo dos 52 anos que abrangem o estudo.

\section{Resultados e Discussão}

A análise das imagens aéreas (Figura 2) mostra que, em 1962, a área total ocupada pelo manguezal era de aproximadamente $120 \mathrm{mil} \mathrm{m}$, em algumas áreas já é possível visualizar ações antrópicas, como construção de moradias e aterramento de vegetação (área em branco). Na década de 80, é possível observar a redução da vegetação, sendo a área de ocupação calculada em 131,4 mil m². Nota-se que a área da mancha urbana se estendeu sobre o corpo d'água através de palafitas, retificando o canal de drenagem natural.
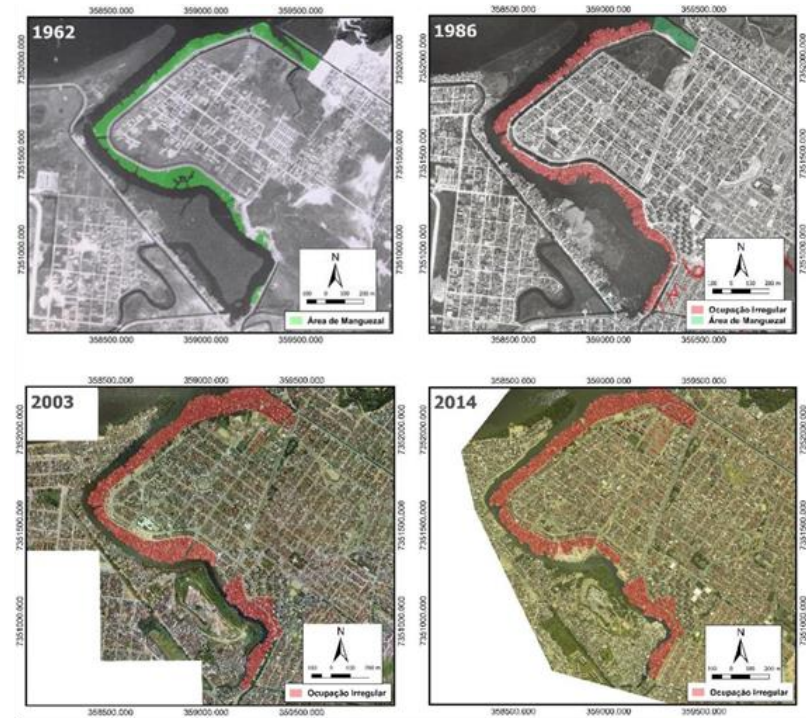

Figura 2: Delimitação das áreas de manguezal e ocupação irregular nos anos de 1962, 1986, 2003 e 2014, respectivamente, no município de Santos.

Em 2003, a área de manguezal foi totalmente ocupada, totalizando uma área de 216,8 mil m². Em 2014, houve uma redução de ocupações irregulares na área (cerca de 10\%) devido a ocorrência de incêndios e ações de fiscalização e políticas habitacionais, totalizando aproximadamente $196 \mathrm{mil} \mathrm{m} \mathrm{m}^{2}$ de área de ocupação. A Tabela I apresenta a metragem das áreas de manguezal e de ocupação irregular ao longo dos anos, verificada através das imagens.

Tabela I. Áreas de manguezal e ocupação irregular ao longo dos anos $(\mathrm{mil} \mathrm{m²})$

\begin{tabular}{ccccc}
\hline Área $\left(\mathbf{m i l ~ m}^{2}\right)$ & $\mathbf{1 9 6 2}$ & $\mathbf{1 9 8 6}$ & $\mathbf{2 0 0 3}$ & $\mathbf{2 0 1 4}$ \\
\hline Manguezal & 120,0 & 17,6 & - & - \\
Ocupação & - & 131,4 & 216,8 & 195,7 \\
\hline
\end{tabular}




\section{Conclusão}

O desenvolvimento econômico na região da Baixada Santista, após a década de 60, especificamente no município de Santos, ocasionou um crescimento desordenado da população e por falta de físcalização, esta população se aglomerou em regiões mais sensíveis, como as áreas de manguezal. A análise das imagens aéreas mostrou que a vegetação de manguezal existente na década de 60 , na região da comunidade do Dique da Vila Gilda, foi totalmente suprimida por ocupações irregulares, como a construção de palafitas, causando problemas sociais, ambientais e urbanos. A utilização de geotecnologias otimiza o monitoramento de áreas com ocupações irregulares, facilitando assim, a fiscalização das mesmas, possibilitando a redução dos impactos ambientais e amenização do problema de cunho social.

\section{Bibliografia}

BRASIL. Lei $\mathrm{N}^{\circ}$ 12.651, de 25 de maio de 2012. Código Florestal Brasileiro. Disponível em: <http://www.planalto.gov.br/ccivil_03/_ato2011-2014/2012/lei/112651.html>. Acesso em: 19 out. 2016.

FABIANO, C.; MUNIZ, S. Dique Vila Gilda: Caminhos para a Regularização. Planejamento e Políticas Públicas - PPP, n. 34, jan./jun, 2010.

IBGE. Instituto Brasileiro de Geografia e Estatística. Resolução do Presidente. n 01/2005 - Altera a caracterização do Sistema Geodésico Brasileiro. Rio de Janeiro. 2005.

IBGE. Instituto Brasileiro de Geografia e Estatística. Censo 2010. Disponível em: <http://censo2010.ibge.gov.br/>. Acesso: 20 out. 2016.

INSTITUTO POLIS. Resumo Executivo de Santos: Litoral Sustentável Desenvolvimento com Inclusão Social. São Paulo, 2012.

LIMA, C. O.; OLIVEIRA, R. C. de. Análise Ambiental de Ocupação nas Áreas de Manguezais no Município de Santos-SP. Revista Geográfica de América Central, Número Especial EGAL, 2011- Costa Rica, II Semestre 2011, pp. 1-13.

MMA. Ministério do Meio Ambiente. Disponível em: <http://www.mma.gov.br/biodiversidade/biodiversidadeaquatica/zona-costeira-e-marinha/manguezais. >Acesso em: 31 ago. 2016.

MMA. Ministério do Meio Ambiente. Resolução CONAMA n 303, de 20 de março de 2002. Disponível em: < http://www.mma.gov.br/port/conama/res/res02/res30302.html>Acesso em: 31 ago. 2016. 
SANTOS, A.L.G. Os manguezais da Baixada Santista -SP. Teses de Mestrado - Programa de Pós-Graduação em Ciência Ambiental, Universidade de São Paulo - São Paulo, 2009.

SIQUEIRA, M. E. de S. A. Turismo e favelas: necessidades e possibilidades: o caso da urbanização da favela do Dique Sambaiatuba, em São Vicente (Baixada Santista - São Paulo). Tese de Doutorado - Programa de PósGraduação em Geografia Humana, Universidade de São Paulo - São Paulo, 2007. 